\title{
Diagnostic value of salivary CRP and IL-6 in patients undergoing anti-TNF-alpha therapy for rheumatic disease
}

\author{
Dorota Sikorska' ${ }^{1}$ - Zofia Orzechowska ${ }^{2} \cdot$ Rafał Rutkowski $^{2} \cdot$ Anna Prymas $^{3} \cdot$ Marta Mrall-Wechta ${ }^{3} \cdot$ \\ Daria Bednarek-Hatlińska ${ }^{3}$ Magdalena Roszak ${ }^{4} \cdot$ Anna Surdacka $^{3} \cdot$ Włodzimierz Samborski $^{1}$. Janusz Witowski ${ }^{2}$
}

Received: 19 May 2018 / Accepted: 27 June 2018 / Published online: 24 July 2018

(c) The Author(s) 2018

\begin{abstract}
Introduction Saliva has been increasingly used as a diagnostic medium for disease detection and monitoring. The aim of this observational, prospective, pilot study was to investigate whether salivary concentrations of CRP and IL-6 correlate with those in serum and with the clinical course of a rheumatic disease.

Materials and methods Nineteen patients with rheumatic disease newly scheduled for anti-TNF $\alpha$ therapy were included. Patients received anti-TNF $\alpha$ treatment (adalimumab, certolizumab, golimumab or infliximab) as per standard protocols. CRP and IL-6 were measured with high-sensitivity immunoassays before and after 12 weeks of therapy, according to standard regimens. The data were analyzed with nonparametric statistics.

Results Concentrations of CRP in saliva correlated significantly with those in serum $(R=0.62 ; p<0.0001)$ and decreased markedly after successful response to treatment. In patients with a limited response to treatment salivary CRP levels increased. In contrast to CRP, the salivary concentrations of IL-6 did not change significantly over the course of therapy and they did not correlate with serum IL-6 concentrations. Salivary levels of neither CRP nor IL-6 corresponded to parameters of oral health and hygiene.
\end{abstract}

Conclusions Salivary CRP but not IL-6 could be of potential use for monitoring the rheumatic disease activity.

Keywords Saliva $\cdot$ C-reactive protein $\cdot$ Interleukin- $6 \cdot$ Rheumatic disease $\cdot$ Biologic therapy

\section{Introduction}

Composition of human saliva depends both on systemic and local factors (Khan et al. 2017). Thus, it may reflect pathophysiological processes relevant to the development both of systemic and local disease (Abdul Rehman et al. 2017; Buczko et al. 2015; Cruz-Almeida et al. 2017). In this respect, saliva has been used as a diagnostic tool to aid

Dorota Sikorska

dorotasikorska@ump.edu.pl

1 Department of Rheumatology and Rehabilitation, Poznan University of Medical Sciences, 28-Czerwca 1956 Street 135/147, 61-545 Poznan, Poland

2 Department of Pathophysiology, Poznan University of Medical Sciences, Poznan, Poland

3 Department of Conservative Dentistry and Endodontics, Poznan University of Medical Sciences, Poznan, Poland

4 Department of Computer Science and Statistics, Poznan University of Medical Sciences, Poznan, Poland the assessment of periodontal disease activity (Korte and Kinney 2016; Podzimek et al. 2016). Moreover, saliva gains an increasing attention as a potential analytical medium for endocrinology, neurology, oncology, and infectious diseases (Clements 2013; Khan et al. 2017; Tabak 2007; Wei and Wong 2012). Identification of disease biomarkers in saliva opens a new avenue for screening populations for disease risk and progression as well as response to treatment (Prasad et al. 2016).

The ease and low cost of saliva collection can make it an ideal diagnostic fluid (Prasad et al. 2016). Thus, the obvious question is how well changes in the saliva reflect the course of a disease.

Several mediators of inflammation, collagen breakdown, and/or bone remodeling change clearly in serum of patients with rheumatic diseases (Buczko et al. 2015; Mirrielees et al. 2010). Since saliva contains many of these serum-derived mediators (Buczko et al. 2015; Khan et al. 2017; Mirrielees et al. 2010), they may be of potential use for the rheumatic disease monitoring. Introduction 
of anti-tumor necrosis factor alpha (anti-TNF $\alpha$ ) therapy for rheumatic disease has revolutionized disease control and greatly improved the outcome of rheumatic disease (Mewar and Wilson 2011). Monitoring of a response to therapy involves the measurement of C-reactive protein (CRP) (Gavrila et al. 2016). Typically, a successful treatment is associated with a suppression of serum CRP levels (Buch et al. 2005).

Thus, we have chosen patients with inflammatory arthritis undergoing therapy with anti-TNF $\alpha$ agents to analyze changes in salivary and systemic CRP. For comparison, salivary and systemic concentrations of inflammatory cytokine interleukin-6 (IL-6) were assessed.

\section{Materials and methods}

\section{Study population}

Nineteen Caucasian patients newly scheduled for anti-TNF $\alpha$ therapy in Poznan University of Medical Sciences were included. All patients fulfilled criteria for the diagnosis of rheumatoid arthritis (RA) according to the American-European Consensus Group classification criteria (Aletaha et al. 2010) $(n=10)$ or the modified New York criteria for ankylosing spondylitis (AS) (van der Linden et al. 1984) $(n=9)$. All patients had an active disease (DAS-28 $>5.1$ or BASDAI $>4$ ) and received anti-TNF $\alpha$ treatment according to the standard European League Against Rheumatism (EULAR) recommendations (Braun et al. 2011; Smolen et al. 2014). None of the patients suffered from a coexisting Sjögren's syndrome. All procedures performed in studies involving human participants were in accordance with the ethical standards of the institutional and/or national research committee and with the 1964 Helsinki Declaration and its later amendments or comparable ethical standards. The study was approved by the Poznan University of Medical Sciences Bioethics Committee (No. 1067/15) and all patients gave their informed consent. The patients were evaluated before and after 12 weeks of therapy.

\section{Treatment}

Patients received anti-TNF $\alpha$ treatment (adalimumab, certolizumab, golimumab, or infliximab) as per standard protocols (Braun et al. 2011; Smolen et al. 2014). All patients had previously been treated with (at least) two synthetic diseasemodifying anti-rheumatic drugs (DMARDs) (methotrexate, leflunomide, sulfasalazine, or cyclosporine) (for RA) or nonsteroid anti-inflammatory drugs (NSAIDs) (for AS) with no satisfactory effects.

\section{Assessment of disease activity}

Disease activity for RA was assessed by the Modified Disease Activity Scores (DAS) - that include different 28-joint counts and erythrocyte sedimentation rate (DAS28 $8_{\text {ESR }}$ ) (Prevoo et al. 1995). The therapeutic response in RA patients was defined by the EULAR criteria (van Gestel et al. 1996). The response to therapy in patients with AS was defined as a reduction of $\geq 50 \%$ in Bath Ankylosing Spondylitis Disease Activity Index (BASDAI) (Brandt et al. 2000; Garrett et al. 1994).

\section{Oral health parameters}

The patients were asked to answer a questionnaire regarding oral hygiene habits. Clinical examination was performed according to standard practices and parameters of dental (DMFT and DMFS), gingival (GI and SBI), and periodontal (PD and CAL) status as well as of oral hygiene status (API and PLI) were assessed by routine methods (Benamghar et al. 1982; Lange et al. 1977; Loe and Silness 1963).

\section{Laboratory analysis}

Unstimulated whole mixed saliva was collected using the Salivette ${ }^{\circledR}$ (Sarstedt Laboratories; Germany) system, with a sponge gently chewed for 5 min (Poll et al. 2007). Samples of serum were collected by routine methods. All samples were taken at the time of clinical examination in a fasting state and then aliquoted and stored at $-80^{\circ} \mathrm{C}$ until assayed. Salivary and serum concentrations of CRP and IL-6 were measured with high-sensitivity ELISA immunoassays (from BioVendor LM; Czech Republic and Diaclone; France, respectively), as per manufacturers' instructions. All other laboratory tests were performed routinely by the hospital central laboratory.

\section{Statistical analysis}

Statistical analysis was performed using STATISTICA 10.0 software (StatSoft Polska, Krakow, Poland). The data are presented as medians and interquartile ranges or as percentages, as appropriate. As the data obtained did not consistently display a normal distribution (as assessed by the Shapiro-Wilk test), they were analyzed with nonparametric statistics using the Wilcoxon test for paired data. Categorized data were analyzed with the chi-square test. Correlations between variables were analyzed with the 
Spearman's rank correlation coefficient. Differences were considered significant at $p<0.05$.

\section{Results}

The patients' baseline characteristics are summarized in Table 1.12 weeks of biologic treatment resulted in a significant improvement in the majority of the patients, with only one patient identified as a non-responder according to EULAR. The favorable response to therapy was reflected by both clinical and biochemical criteria (Table 2). It was also associated with a significant decrease in serum CRP and IL-6 (Table 2).

Table 1 Patients' baseline characteristics $(n=19)$

\begin{tabular}{lc}
\hline Demographic and clinical features & \\
Age (years) & $46(36-61)$ \\
Men (\%) & $10(53 \%)$ \\
Disease duration (years) & $6(3-12)$ \\
Current smoking (\%) & $1(5 \%)$ \\
Oral health parameters & \\
No/mild periodontitis (\%) & $8(42 \%)$ \\
Severe periodontitis (\%) & $11(58 \%)$ \\
Plaque Index (PLI) & $0.7(0.4-1.0)$ \\
Approximal Plaque Index (API) (\%) & $75.0(42.9-100.0)$ \\
Sulcus Bleeding Index (SBI) & $0.0(0.0-0.3)$ \\
Gingival Index (GI) & $0.4(0.0-1.0)$ \\
Probing pocket depth (PD) (mm) & $0.8(0.6-1.3)$ \\
Clinical attachment level (CAL) & $1.4(0.6-2.0)$ \\
DMFT Index & $18.5(15.0-26.0)$ \\
\hline
\end{tabular}

Data presented as medians (and interquartile ranges) or $\%$
Concentrations of CRP in saliva measured in all patients at all points correlated significantly with those in serum $(R=0.62 ; p<0.0001)$ (Fig. 1).

Importantly, these correlations were evident independently at the beginning and after treatment $(R=0.49$; $p=0.031$ and $R=0.63 ; p=0.004$; respectively). The fractional mean changes in serum CRP that occurred as a result of anti-TNF $\alpha$ treatment were reflected by similar percentage changes in CRP levels in saliva $(R=0.51 ; p=0.025)$. In patients with successful response to treatment significant decrease in salivary CRP levels were observed $(p=0.0005)$ (Fig. 2). In three patients with a limited response to treatment (with a relatively small decrease in clinical disease activity: DAS28 or BASDAI) and with increase of serum CRP levels, an increase in salivary CRP concentrations after treatment was also observed, although it was not statistically significant ( $p=0.25)$ (Fig. 2).

Whereas in a single patient defined as an EULAR nonresponder, serum CRP concentrations decreased, but still remained high in absolute values (97.96 vs. $42.11 \mathrm{mg} / \mathrm{l}$ ), salivary CRP levels were both high at baseline and further increased with time (3.72 vs. $6.41 \mathrm{mg} / \mathrm{l}$; NS).

In addition to correlations with serum CRP, salivary CRP correlated with other standard laboratory markers used in RA monitoring [ESR $(R=0.60 ; p<0.001)$ and $\mathrm{N} / \mathrm{L}$ ratio $(R=0.51 ; p=0.001)]$. There was no consistent association between salivary CRP and oral health parameters.

In contrast to apparent correlation between systemic and salivary CRP, the concentrations of IL-6 in saliva did not correlate with those in serum (Fig. 3), either before or after treatment.

There was also no correlation between salivary CRP and IL-6 levels (both before and after treatment). Interestingly,
Table 2 Selected parameters before and after treatment

\begin{tabular}{lccc}
\hline & Before treatment $(n=19)$ & $\begin{array}{l}\text { After 12 weeks of treat- } \begin{array}{l}p \text { value } \\
\text { ment }(n=19)\end{array} \\
\text { (Wilcoxon } \\
\text { test) }\end{array}$ \\
\hline DAS28 $_{(\mathrm{ESR})}($ for RA; $n=10)$ & $6.2(5.5-6.4)$ & $3.5(2.8-4.5)$ & $\mathbf{0 . 0 0 5}$ \\
BASDAI (for AS; $n=9)$ & $7.9(6.6-8.6)$ & $2.8(2.0-4.2)$ & $\mathbf{0 . 0 0 8}$ \\
ESR $(\mathrm{mm} / \mathrm{h})$ & $30(8-70)$ & $6(4-24)$ & $\mathbf{0 . 0 0 2}$ \\
WBC $\left(10^{3} / \mathrm{l}\right)$ & $9.3(8.2-9.9)$ & $8.0(6.4-9.7)$ & $\mathbf{0 . 0 1 5}$ \\
N/L ratio & $3.0(2.4-3.6)$ & $1.4(1.2-2.1)$ & $<\mathbf{0 . 0 0 1}$ \\
Serum CRP $(\mathrm{mg} / \mathrm{l})$ & $10.24(4.65-24.31)$ & $1.52(0.54-4.13)$ & $\mathbf{0 . 0 1 0}$ \\
Serum IL-6 $(\mathrm{pg} / \mathrm{ml})$ & $14.23(5.03-34.61)$ & $2.32(1.49-25.14)$ & $\mathbf{0 . 0 4 4}$ \\
Salivary CRP $(\mathrm{mg} / \mathrm{l})$ & $0.30(0.02-3.72)$ & $0.05(0.00-1.87)$ & 0.098 \\
Salivary IL-6 $(\mathrm{pg} / \mathrm{ml})$ & $1.91(0.94-2.43)$ & $1.48(0.98-2.78)$ & 0.811 \\
\hline
\end{tabular}

Bold values are statistically significant $(p<0.05)$

Data presented as the median (interquartile range)

DAS28, 28-joint disease activity score; BASDAI, bath ankylosing spondylitis disease activity Index; ESR, erythrocyte sedimentation rate; CRP, C-reactive protein; N/L ratio, neutrophils to lymphocytes ratio; IL-6, interleukin-6; RA, rheumatoid arthritis; AS, ankylosing spondylitis 


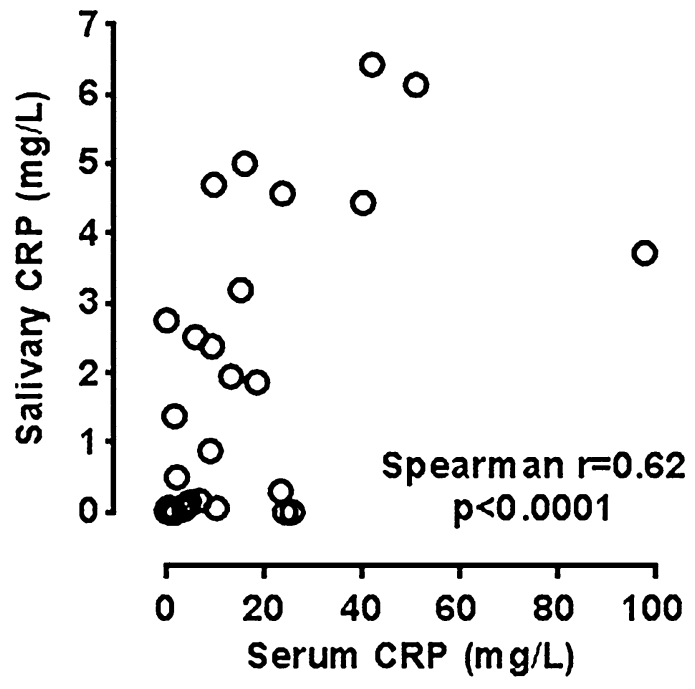

Fig. 1 Correlation between serum and salivary CRP

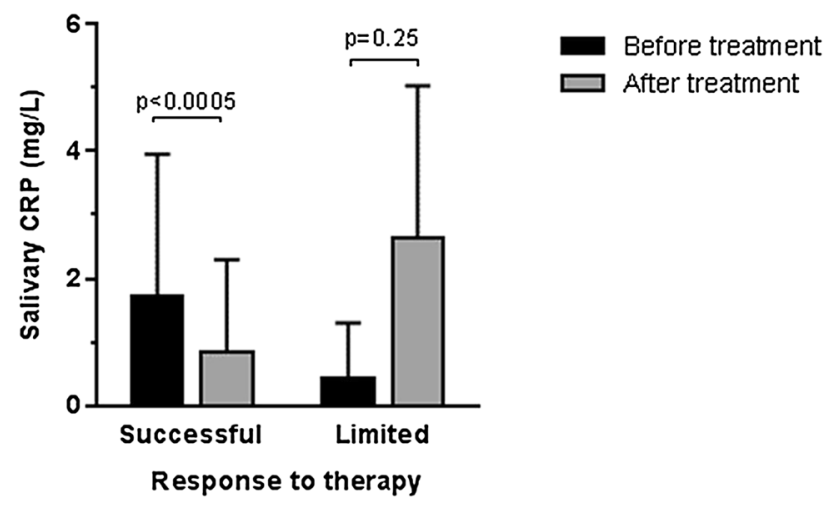

Fig. 2 Changes in salivary CRP levels after treatment

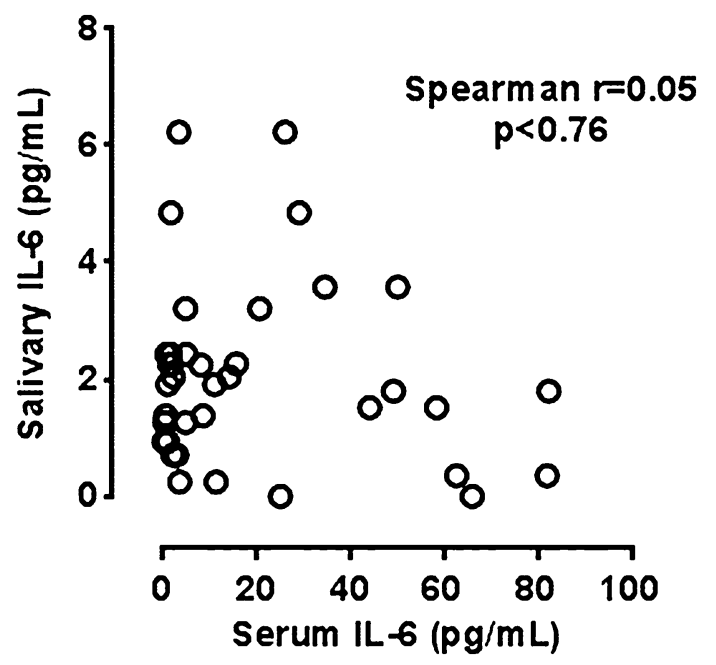

Fig. 3 Correlation between salivary and serum IL-6

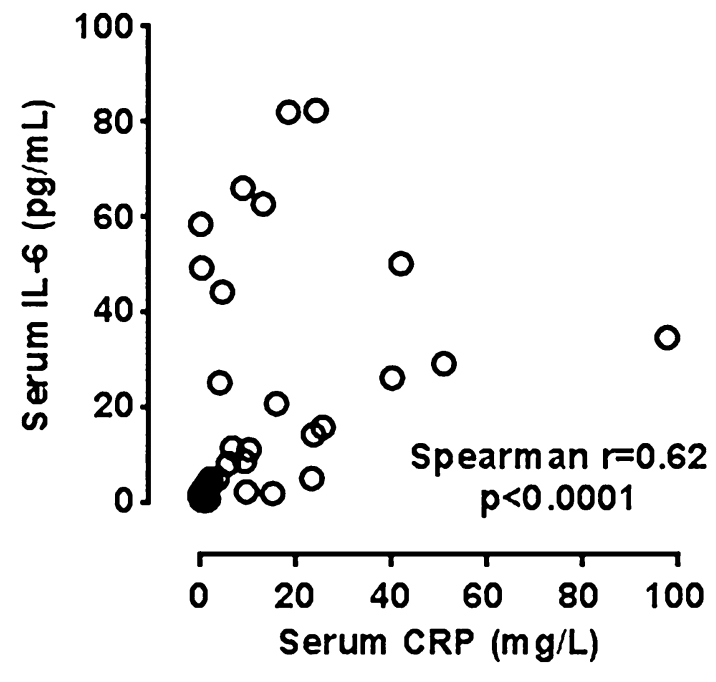

Fig. 4 Correlation between serum CRP and serum IL-6

however, there was still a correlation between serum CRP and serum IL-6 $(R=0.62 ; p<0.001)$ (Fig. 4).

The salivary concentrations of IL- 6 did not change significantly over the course of anti-TNF $\alpha$ treatment and they did not correlate with other systemic inflammatory parameters (ESR, leukocytes, N/L ratio).

\section{Discussion}

The main observation of this exploratory study was that the salivary concentrations of CRP in patients with rheumatic disease correlated significantly with those in serum and paralleled changes in the disease activity as reflected both by clinical and standard biochemical criteria.

To the best of our knowledge, it is the first assessment of how well changes in the salivary CRP concentrations reflect the course of a rheumatic disease. While few earlier studies have reported on the potential use of salivary CRP as an indicator of systemic inflammation (Abdul Rehman et al. 2017; Pallos et al. 2015), especially in neonatology (where non-invasive collection of diagnostic material is of particular importance) (Iyengar et al. 2014; Omran et al. 2017a, b).In this respect, Iyengar et al. demonstrated that salivary CRP is a good index of clinically relevant serum CRP thresholds in neonates (Iyengar et al. 2014). Similar results were obtained also for adults with chronic diseases, including cardiovascular (Labat et al. 2013; Out et al. 2012) and renal disease (Pallos et al. 2015). Our data indicate that salivary CRP could also reflect the activity of rheumatic disease.

Surprisingly, there was no consistent association between salivary CRP and oral health parameters. In this regard, previous studies produced unequivocal results with both the absence (Redman et al. 2016) (Torumtay et al. 2016) and the 
presence (Nethravathy et al. 2014; Shojaee et al. 2013) of associations of between salivary CRP and the periodontal status. It is possible that an intense systemic inflammatory response in rheumatic disease overshadows that resulting from local lesions in the oral cavity.

We did not observe significant changes in salivary IL-6 over the course of anti-TNF $\alpha$ treatment and we found no correlation of salivary IL-6 with serum levels of either IL-6 or other inflammatory parameters (CRP, ESR, leukocytes, $\mathrm{N} / \mathrm{L}$ ratio). Other studies detected only a weak correlation between salivary and serum IL-6 levels (Dekker et al. 2017; Slavish et al. 2015). At the same time, patients with RA were reported to have a tendency for higher levels of IL-6 in saliva (Silvestre-Rangil et al. 2017). The main source of the increase levels of CRP in saliva could be crevicular fluid, due to the greater incidence of periodontal disease observed in these patients (Rajkarnikar et al. 2013). Although in our study there was no consistent correlation between salivary IL-6 and periodontal parameters, which may result from a small study group.

An obvious limitation of our study is the small and heterogeneous group of patients analyzed. Thus, it should be viewed as preliminary and be validated in an independent and larger more homogeneous patients' population.

\section{Conclusions}

In conclusion, salivary concentrations of CRP, but not of IL-6, in patients with rheumatic disease significantly decrease over the course of successful anti-TNF $\alpha$ therapy and parallel changes in the disease activity. In addition, they reflect serum concentrations of both CRP and other surrogate inflammatory markers. Therefore, the measurement of salivary CRP could be of potential use for the assessment of the rheumatic disease activity.

Acknowledgements This work was supported by the Poznan University of Medical Sciences (Grant no. 502-14-02230375-10572).

\section{Compliance with ethical standards}

Conflict of interests The authors declare that they have no conflict of interest.

Open Access This article is distributed under the terms of the Creative Commons Attribution 4.0 International License (http://creativeco mmons.org/licenses/by/4.0/), which permits unrestricted use, distribution, and reproduction in any medium, provided you give appropriate credit to the original author(s) and the source, provide a link to the Creative Commons license, and indicate if changes were made.

\section{References}

Abdul Rehman S, Khurshid Z, Hussain Niazi F, Naseem M, AlWaddani H, Sahibzada HA, Sannam Khan R (2017) Role of salivary biomarkers in detection of cardiovascular diseases (CVD). Proteomes 5:21. https://doi.org/10.3390/proteomes5030021

Aletaha D et al (2010) 2010 rheumatoid arthritis classification criteria: an American College of Rheumatology/European League Against Rheumatism collaborative initiative. Ann Rheum Dis 69:1580 1588. https://doi.org/10.1136/ard.2010.138461

Benamghar L, Penaud J, Kaminsky P, Abt F, Martin J (1982) Comparison of gingival index and sulcus bleeding index as indicators of periodontal status. Bull World Health Organ 60:147-151

Brandt J et al (2000) Successful treatment of active ankylosing spondylitis with the anti-tumor necrosis factor alpha monoclonal antibody infliximab. Arthritis Rheum 43:1346-1352. https://doi.org/10.1002/1529-0131(200006)43:6<1346:aidanr $18>3.0 . c 0 ; 2-\mathrm{e}$

Braun J et al (2011) 2010 update of the ASAS/EULAR recommendations for the management of ankylosing spondylitis. Ann Rheum Dis 70:896-904. https://doi.org/10.1136/ard.2011.151027

Buch MH, Seto Y, Bingham SJ, Bejarano V, Bryer D, White J, Emery $P(2005)$ C-reactive protein as a predictor of infliximab treatment outcome in patients with rheumatoid arthritis: defining subtypes of nonresponse and subsequent response to etanercept. Arthritis Rheum 52:42-48. https://doi.org/10.1002/art.20711

Buczko P, Zalewska A, Szarmach I (2015) Saliva and oxidative stress in oral cavity and in some systemic disorders. J Physiol Pharmacol 66:3-9

Clements AD (2013) Salivary cortisol measurement in developmental research: where do we go from here? Dev Psychobiol 55:205-220. https://doi.org/10.1002/dev.21025

Cruz-Almeida Y, Aguirre M, Sorenson H, Tighe P, Wallet SM, Riley JL 3rd (2017) Age differences in salivary markers of inflammation in response to experimental pain: does venipuncture matter? J Pain Res 10:2365-2372. https://doi.org/10.2147/jpr.s138460

Dekker RL et al (2017) Salivary biomarkers oral inflammation, and functional status in patients with heart failure. Biol Res Nurs 19:153-161. https://doi.org/10.1177/1099800416665197

Garrett S, Jenkinson T, Kennedy LG, Whitelock H, Gaisford P, Calin A (1994) A new approach to defining disease status in ankylosing spondylitis: the Bath Ankylosing Spondylitis Disease Activity Index. J Rheumatol 21:2286-2291

Gavrila BI, Ciofu C, Stoica V (2016) Biomarkers in rheumatoid arthritis, what is new? J Med Life 9:144-148

Iyengar A, Paulus JK, Gerlanc DJ, Maron JL (2014) Detection and potential utility of C-reactive protein in saliva of neonates. Front Pediatrics 2:131. https://doi.org/10.3389/fped.2014.00131

Khan RS, Khurshid Z, Yahya Ibrahim Asiri F (2017) Advancing pointof-care (PoC) testing using human saliva as liquid biopsy. Diagnostics (Basel, Switzerland) 7:39. https://doi.org/10.3390/diagn ostics7030039

Korte DL, Kinney J (2016) Personalized medicine: an update of salivary biomarkers for periodontal diseases. Periodontology 2000(70):26-37. https://doi.org/10.1111/prd.12103

Labat C, Temmar M, Nagy E, Bean K, Brink C, Benetos A, Back M (2013) Inflammatory mediators in saliva associated with arterial stiffness and subclinical atherosclerosis. J Hypertens 31:22512258. https://doi.org/10.1097/hjh.0b013e328363dccc (discussion 2258)

Lange DE, Plagmann HC, Eenboom A, Promesberger A (1977) Clinical methods for the objective evaluation of oral hygiene. Dtsch Zahnarztliche Z 32:44-47

Loe H, Silness J (1963) Periodontal disease in pregnancy. I. Prevalence and severity. Acta Odontol Scand 21:533-551 
Mewar D, Wilson AG (2011) Treatment of rheumatoid arthritis with tumour necrosis factor inhibitors. Br J Pharmacol 162:785-791. https://doi.org/10.1111/j.1476-5381.2010.01099.x

Mirrielees J, Crofford LJ, Lin Y, Kryscio RJ, Dawson DR 3rd, Ebersole JL, Miller CS (2010) Rheumatoid arthritis and salivary biomarkers of periodontal disease. J Clin Periodontol 37:1068-1074. https ://doi.org/10.1111/j.1600-051X.2010.01625.x

Nethravathy RR, Alamelu S, Arun KV, Kumar TS (2014) Evaluation of circulatory and salivary levels of heat shock protein 60 in periodontal health and disease. Indian J Dent Res 25:300-304. https ://doi.org/10.4103/0970-9290.138317

Omran A, Ali M, Saleh MH, Zekry O (2017a) Salivary C-reactive protein and mean platelet volume in diagnosis of late-onset neonatal pneumonia. Clin Respir J. https://doi.org/10.1111/crj.12723

Omran A, Maaroof A, Saleh MH, Abdelwahab A (2017b) Salivary C-reactive protein, mean platelet volume and neutrophil lymphocyte ratio as diagnostic markers for neonatal sepsis. J Pediatria. https://doi.org/10.1016/j.jped.2017.03.006

Out D, Hall RJ, Granger DA, Page GG, Woods SJ (2012) Assessing salivary C-reactive protein: longitudinal associations with systemic inflammation and cardiovascular disease risk in women exposed to intimate partner violence. Brain Behav Immun 26:543-551. https://doi.org/10.1016/j.bbi.2012.01.019

Pallos D, Leao MV, Togeiro FC, Alegre L, Ricardo LH, Perozini C, Ruivo GF (2015) Salivary markers in patients with chronic renal failure. Arch Oral Biol 60:1784-1788. https://doi.org/10.1016/j. archoralbio.2015.09.008

Podzimek S, Vondrackova L, Duskova J, Janatova T, Broukal Z (2016) Salivary markers for periodontal and general diseases. Dis Markers 2016:9179632. https://doi.org/10.1155/2016/9179632

Poll EM, Kreitschmann-Andermahr I, Langejuergen Y, Stanzel S, Gilsbach JM, Gressner A, Yagmur E (2007) Saliva collection method affects predictability of serum cortisol. Clin Chim Acta 382:15-19. https://doi.org/10.1016/j.cca.2007.03.009

Prasad S, Tyagi AK, Aggarwal BB (2016) Detection of inflammatory biomarkers in saliva and urine: potential in diagnosis, prevention, and treatment for chronic diseases. Exp Biol Med (Maywood, NJ) 241:783-799. https://doi.org/10.1177/1535370216638770

Prevoo ML, van't Hof MA, Kuper HH, van Leeuwen MA, van de Putte LB, van Riel PL (1995) Modified disease activity scores that include twenty-eight-joint counts. Development and validation in a prospective longitudinal study of patients with rheumatoid arthritis. Arthritis Rheum 38:44-48
Rajkarnikar J, Thomas BS, Rao SK (2013) Inter-relationship between rheumatoid arthritis and periodontitis. Kathmandu Univ Med J (KUMJ) 11:22-26

Redman RS et al (2016) Salivary and serum procalcitonin and C-reactive protein as biomarkers of periodontitis in United States veterans with osteoarthritis or rheumatoid arthritis. Biotech Histochem 91:77-85. https://doi.org/10.3109/10520295.2015.1082625

Shojaee M, Fereydooni Golpasha M, Maliji G, Bijani A, Aghajanpour Mir SM, Mousavi Kani SN (2013) C-reactive protein levels in patients with periodontal disease and normal subjects. Int J Mol Cell Med 2:151-155

Silvestre-Rangil J, Bagan L, Silvestre FJ, Martinez-Herrera M, Bagan J (2017) Periodontal, salivary and IL-6 status in rheumatoid arthritis patients. A cross-sectional study. Med Oral Patol Oral Cir Bucal 22:e595-e600. https://doi.org/10.4317/medoral.21937

Slavish DC, Graham-Engeland JE, Smyth JM, Engeland CG (2015) Salivary markers of inflammation in response to acute stress. Brain Behav Immun 44:253-269. https://doi.org/10.1016/j. bbi.2014.08.008

Smolen JS et al (2014) EULAR recommendations for the management of rheumatoid arthritis with synthetic and biological diseasemodifying antirheumatic drugs: 2013 update. Ann Rheum Dis 73:492-509. https://doi.org/10.1136/annrheumdis-2013-204573

Tabak LA (2007) Point-of-care diagnostics enter the mouth. Ann N Y Acad Sci 1098:7-14. https://doi.org/10.1196/annals.1384.043

Torumtay G, Kirzioglu FY, Ozturk Tonguc M, Kale B, Calapoglu M, Orhan $H$ (2016) Effects of periodontal treatment on inflammation and oxidative stress markers in patients with metabolic syndrome. J Periodontal Res 51:489-498. https://doi.org/10.1111/jre.12328

van der Linden S, Valkenburg HA, Cats A (1984) Evaluation of diagnostic criteria for ankylosing spondylitis. A proposal for modification of the New York criteria. Arthritis Rheum 27:361-368

van Gestel AM, Prevoo ML, van't Hof MA, van Rijswijk MH, van de Putte LB, van Riel PL (1996) Development and validation of the European League Against Rheumatism response criteria for rheumatoid arthritis. Comparison with the preliminary American College of Rheumatology and the World Health Organization/ International League against rheumatism criteria. Arthritis Rheum 39:34-40

Wei F, Wong DT (2012) Point-of-care platforms for salivary diagnostics. Chin J Dent Res 15:7-15 